\title{
Adaptive transport layer protocol for highly dynamic environment
}

\author{
Hala Eldaw Idris Jubara*, Sharifah Hafizah Syed Ariffin, Shiela N Fisal, Nurul Muazzah Abdul Latiff, \\ Sharifah K Syed Yusof and Rozeha Rashid
}

\begin{abstract}
Computer and wireless communication require Internet accessibility at anytime and anywhere; this includes in a high-speed mobile station such as in speedy trains, fast moving cars as vehicle-to-infrastructure communication. However, wireless Quality of Service (QoS) provisioning in such an environment is more challenging. This increased the development of numerous schemes concerning the need of smooth handover of the mobile nodes. Conversely, transport layer (L4 in ISO layers) protocols such as stream control transmission protocol can support such a seamless handover in high-speed mobility users. This article highlights on the issues of moving users in mobile WiMAX networks. An adaptation of transport layer protocol of the high mobility vehicle that supports seamless handover can guarantee and maintain QoS for rapid handover rates. The results show an improvement of L4 protocol in terms of delay time and throughput in order to enable efficient and robust mobility aware protocols.
\end{abstract}

Keywords: Cross-layer, Handover delay, Adaptive mobility, High speed

\section{Introduction}

With more users moving around in need of Internet connection from their home to their office, vehicular ad-hoc network (VANETs) has increasingly become popular. However, to have infrastructure of $3 \mathrm{G}$ and $4 \mathrm{G}$ around VANET expands its usage by attaching the users to the backbone infrastructure for additional support and usage applications. Thus, in VANET there are two types of communication, which are vehicles-to-vehicle $(\mathrm{V} 2 \mathrm{~V})$ and vehicle-to-infrastructure (V2I). V2V deals with communication between vehicles themselves, while V2Itransmits information between vehicles and the fixed infrastructure which are installed on the sides of the road. This infrastructure includes gateways or base stations that provide services such as Internet access. VANET is very similar to mobile ad-hoc network (MANETs). However, the network topology in vehicular networks is highly dynamic and the topology is often constrained by the road structure $[1,2]$.

Furthermore, V2I is likely to encounter a lot of obstacles such as poor channel quality and connectivity due to high moving speeds. Thus, there is a crucial need for

\footnotetext{
* Correspondence: haldaw@hotmail.com

UTM MIMOS CoE Communication and Information, Faculty of Electrical Engineering, Universiti Technologi Malaysia, Skudai, Johor 81310, Malaysia
}

effective protocols that take the specific characteristics of vehicular networks into account $[3,4]$.

Most of the existing transport layer techniques proposed for mobility cannot deal with mobility on their own, since they depend on the network layer mobility management required by handovers. The main purpose is simply to minimize the degradation of transport layer performance caused by handovers. Some of the newly emerging protocols, such as stream control transmission protocol (SCTP), suggest the possibility of independent management of mobility by the transport layer. The multi-homing features of SCTP provide a basis for mobility support since it allows a mobile user to add new IP address, while holding the old IP address already assigned to itself [5-9].

When the vehicle moves fast in V2I from on base station to another; the current Internet session will experience long handover delay. To reduce this delay we proposed an enhancement over existing protocol known as seamless IP diversity-based generalized mobility architecture (SIGMA) as shown in Figure 1. SIGMA uses a location manager (LM) to reduce handover delay caused of diversity in the network as mentioned in Figure 1. Conversely, SIGMA experiences more handover delay and packet loss rate when the handover rate is high (high moving speed). A crosslayer design of transport layer (L4) and data link layer (L2)

\section{勿}

(ㄷ) 2012 Jubara et al.; licensee Springer. This is an Open Access article distributed under the terms of the Creative Commons Attribution License (http://creativecommons.org/licenses/by/2.0), which permits unrestricted use, distribution, and reproduction in any medium, provided the original work is properly cited. 


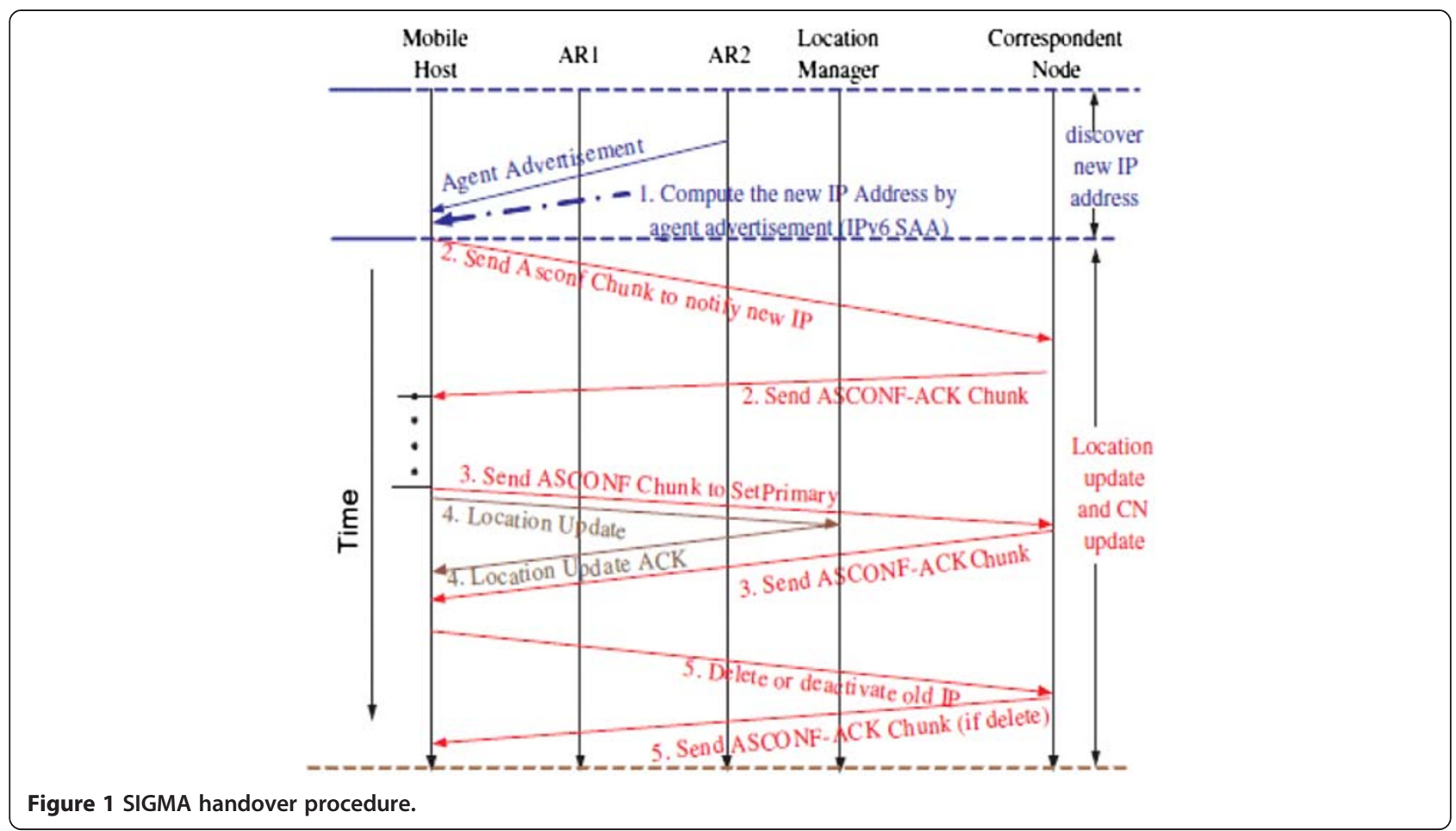

is proposed in order to optimize the performance of SIGMA. To exploit SIGMA IP diversity and overcome the weakness for high speeds, a cross-layer design makes L4 aware about the movement of the vehicle using the radio signal strength indicator (RSSI) of L2.

The rest on the article is organized as follows. The following section presents the highly dynamic environments literature review, and the related works. An overview of vehicular network mobility management in terms of five requirements is detailed in "Vehicular network mobility management". The cross-layer design of the high speed to overcome the problem statement is discussed in Section "Proposed transport layer adaptation for high-speed vehicle". Section "Simulation topology" describes simulation topology and parameters. Section "Results and discussion" presents results of the protocol design mentioned, and the final section concludes the article.

\section{Highly dynamic environments}

Mobility management is one of the most challenging research issues for vehicular networks to support a variety of intelligent transportation system (ITS) applications. Some traditional mobility management schemes for Internet as MANET have to meet the requirements of vehicular networks, and characteristics of vehicular networks (e.g., high mobility). Therefore, mobility management solutions developed specifically for vehicular networks would be required.

\section{Vehicular network mobility management}

The mobility management in vehicular networks should guarantee the reachability to correspondent nodes $(\mathrm{CN})$ in the Internet as well as the global reachability to mobile nodes (MNs). For this reason, the mobility management has confined requirements such as seamless mobility, fast handover, IPv6 support, high mobility speed, and movement detection $[2,6,10]$. VANET mobility requirements are summarized in Table 1.

\section{Related studies}

Mobility support for users and vehicular networks requires network connection as interactive and real-time applications become increasingly important. Therefore, many seamless-mobility approaches have been developed to avoid service disruption and minimize the awareness of service degradation while the mobile device is moving fast. The study of [1] proposed a cross-layer scheme called CEAL to support mobility of transport layer protocol mSCTP using data link layer primitives. The performance evaluation shows less handover delay in WLAN environments. In $[11,13,14]$, various approaches that support seamless and lossless handover in the high-speed transportation system were described. The study of [11] exploits prediction technique to improve and optimize the performance in high-speed environments. Thus, there would be no problem regarding insufficient time in connection 
Table 1 Mobility management flows

\begin{tabular}{|c|c|}
\hline Seamless mobility & $\begin{array}{l}\text { Mobility of vehicles should be seamless regardless of vehicle's location and wireless technology }[1,11] . \text { Moreover, } \\
\text { accessibility and service continuity should be guaranteed }\end{array}$ \\
\hline Fast handover & $\begin{array}{l}\text { Fast handover is needed for delay sensitive ITS applications (e.g., safety, Internet access, etc.). Fast handover is also a crucial } \\
\text { requirement for wireless networks with small coverage area (e.g., WiFi network), since the vehicle with high speed spends } \\
\text { short period of time at each point of attachment (e.g., Base station). Consequently high handover rate }\end{array}$ \\
\hline IPv6 support & $\begin{array}{l}\text { The global reachability requires a comprehensive reliable routable IP address for each MN. IPv6 with large address space } \\
\text { can support a unique address for all mobile devices in the vehicles. In addition, IPv6 also has better support of security and } \\
\text { quality of service (QOS) which are the necessary requirements of ITS applications }\end{array}$ \\
\hline High mobility speed & $\begin{array}{l}\text { The Internet access is expected to be constantly connected regardless of the movement speed. It is highly desirable to } \\
\text { make these contents available and reliable regardless of time, place, fixed, or mobile. As the speed of vehicle increases, the } \\
\text { successful probability of handover decreases as the handover execution time is increased }\end{array}$ \\
\hline Movement detection & $\begin{array}{l}\text { Vehicle needs to detect the availability of different types of access networks (e.g., WiMAX base station) known as data link } \\
\text { layer handover (L2), and obtain addresses in these networks for communication }\end{array}$ \\
\hline Location management & $\begin{array}{l}\text { Location management scheme, which deals with the storage, maintenance, and retrieval of MN location information, is } \\
\text { needed in VANETs [12] }\end{array}$ \\
\hline
\end{tabular}

establishment as the speed increase. A study in [14] also suggested that 802.21 centric approaches used to exploit a prior knowledge method where network information is gathered from both mobile terminal and network infrastructure to establish an earlier connection with the new subnet. In order to reduce the effect of service interruption in the high movement speed environment, the study of [13] propose a packet forwarding control scheme to select a common ahead point as the tunnel source to forward packets. Using this method, packets can be sent through a shorter delivery path during handover. The authors of [3] proposed network mobility protocol for VANETs NEMO protocol for VANET in highway. Since every car is moving in a fixed direction with high moving speed, the car adopting this protocol can acquire IP address from the VANET through the V2V communications. In [4], they presented a cross-layer handover scheme, called vehicular fast handover scheme, where the physical layer information is shared with the MAC layer, to reduce the handover delay. Using lower layer's handovers, the transportation layer will not be aware of the handover which may cause packet loss and degradation of the network QoS.

Transport layer-based approach such as mobile SCTP (mSCTP) influences the ability of SCTP to have multiple IP addresses per association. mSCTP utilizes a feature of SCTP, which allows an MN dynamically switch between available access networks thus affecting seamless handovers. The authors of [6] provide analysis that mSCTP can provide lower handover latency than mobile IP and give much smaller handover latency for vertical handover. Hierarchical transport layer mobility protocol which is a new proposed option that deals with the local and global mobilities to improve throughputs during the handoff period. This protocol exploits the dynamic address reconfiguration feature of SCTP and introduces an anchor mobility uniting order to complete more efficient handoff procedures. A novel error recovery mechanism associated with a handover was discussed in [8] where the error recovery time of this mechanism is analyzed and compared to that of the plain SCTP for handover cases. The previous work mainly focuses on low or medium speeds. However, the needs to maintain a seamless communication in the high-speed situations is becoming highly attractive and challenging issue that needs to be tackled $[3,4,11]$.

Proposed transport layer adaptation for high-speed vehicle In this cross-layer design (SCTPcd) information from multiple protocol layers [data link (L2), network (L3), and transport (L4) layers] of the vehicle can effectively be exchanged to improve performance of the mobility management scheme. However, L2 and L4 mainly exchange messages to adapt the speed of the vehicle (L2) with SIGMA protocol design (L4). To evaluate the performance of this design, a network scenario of four BSs connected to $\mathrm{CN}$ via the Internet using two access routers (2ARs). This network using one SCTP association of SIGMA as mentioned in [5,15-19] as appears in Figure 2. In this scenario, the vehicle moves from serving $\mathrm{BS}$ (SBS) to the target BS (TBS) so the current running Internet communication will switch from SBS to TBS with same technology (WiMAX BSs). Long handover procedure may cause delay in data communication that leads to service disruption. On other hands, in the movement speed may give adverse impact to the network performance when using SIGMA protocol due to insufficient time to prepare for handover and therefore, high handover rate and packet loss. Thus, the cross-layer design handled these challenges much more efficiently using transport layer protocol SIGMA and available information from data link layer (RSSI).

Figure 3 shows the state diagram of the cross-layer (SCTPcd) as vehicle moves from first state in SBS towards TBS along this time signal strength becomes low. Then vehicle inter through handover area state 2 , at that time L2, sends to higher layers LinkStatusChange.ind message. State 3, the vehicle inside handover area and communication with SBS is stopped so it sends L2 messages to upper 


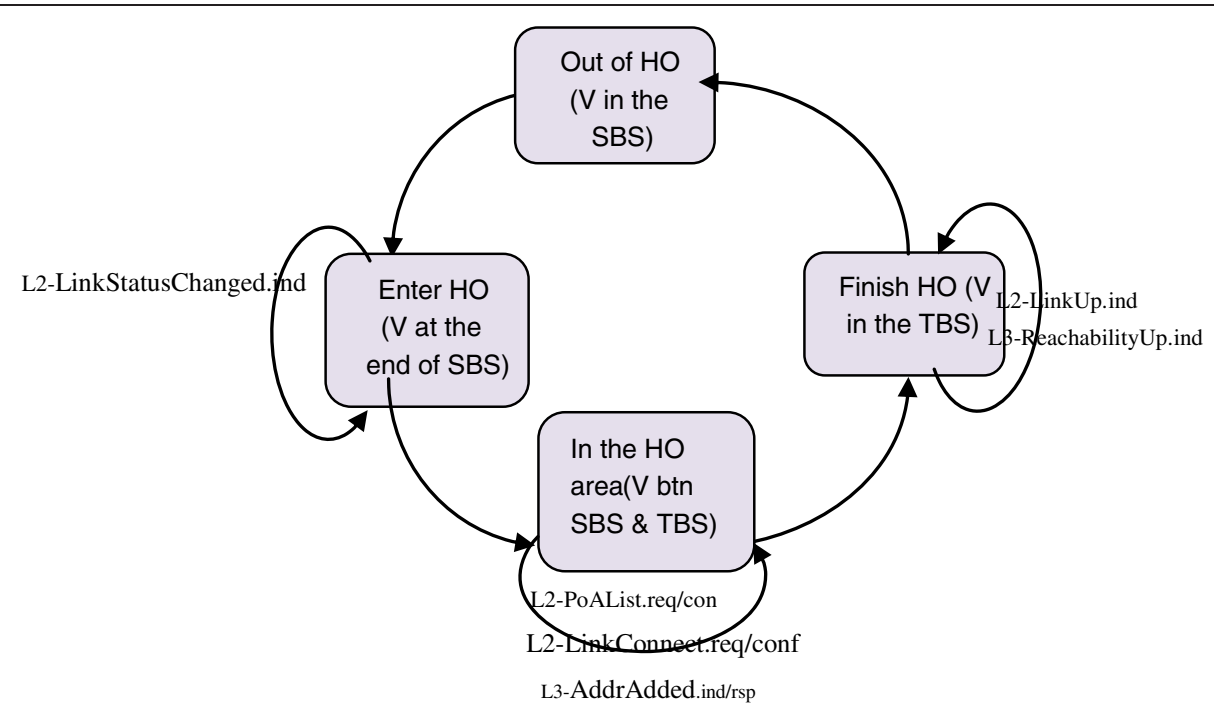

Figure 2 State Diagram of the proposed cross layer design.

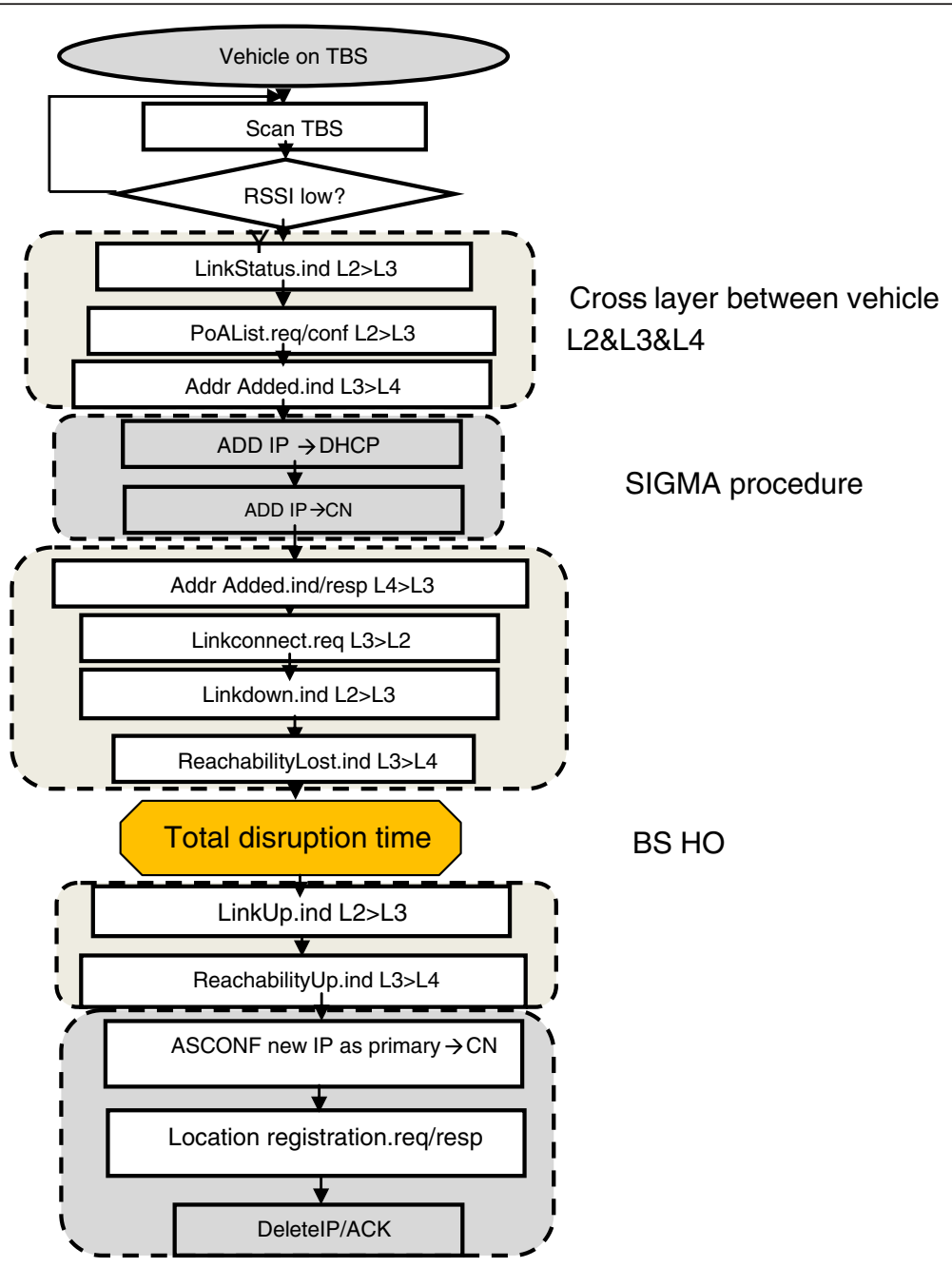

Figure 3 Cross-layer design algorithm. 
layer asking the number of BSs, LinkConnect.ind to TBS. Last is state 4, which is the finishing of handover, L2 receives LinkUp.ind to indicate signal strength going up and L3 message to inform of reaching network. Figure 4 shows the timing diagram of the proposed cross-layer to describe the flow of the handover messages between BS and vehicle (L2 handover) and vehicle and CN (L4 handover SCTP). On another side, Figure 5 mentions the idea of cross-layer handover with the L2 handover message of BS, L4 of SCTP protocol and high-speed vehicle.

\section{Handover procedure of SCTPcd}

Handover procedure of this cross-layer design is depicted in Figure 5. It contains handover delay of two protocol layers (L2) handover delay and (L4) handover delay. For data-link layer, the handover delay contains mobile WiMAX BS signaling messages to initiate (trigger) and execute the handover. However, most of L4 handover delay of SIGMA protocol using in this design is for SCTP's Set Primary chuck as well as delete old IP (ASCONF SETPRIMARY/DEL-IP) messages of handover plus Round Trip Time (RTT) of messages between vehicle and CN (about 1-10 ms). Even so, the link delay to update LM does not affect handover delay for SIGMA so the time of location ranging request and response (REG.REQ/RSP) are negligible [20]. Finally, the total handover delay time during the cross-layer design:

$$
\begin{aligned}
\text { Total handover delay }\left(T_{\mathrm{HO}}\right) & =\mathrm{L} 2+\mathrm{L} 4(\mathrm{ASCONFSET} \\
& -\mathrm{PRIMARY} / \mathrm{DEL}-\mathrm{IP})+\mathrm{RTT}
\end{aligned}
$$

where L2 data link layer delay, L4: Transport layer delay.

\section{Simulation topology}

To evaluate our idea, a simulation used was OMNET++ cooperatively with MATLAB. As shown in Figure 4, the vehicle is multi-homed node moving with speed of 70$120 \mathrm{~km} / \mathrm{h}$ along highway and connected to the Internet through wireless access point (WiMAX BS). The coverage area of each BS about $2000 \mathrm{~m}$, and the overlapping region between two BSs is $200 \mathrm{~m}$. Moreover, from the network side, each two BSs connected to one AR, and both of two ARs connect one MAP. This MAP directly joins this network to the Internet as Gateway. As shown in Figure 2, other part of the network connect the $\mathrm{CN}$ as

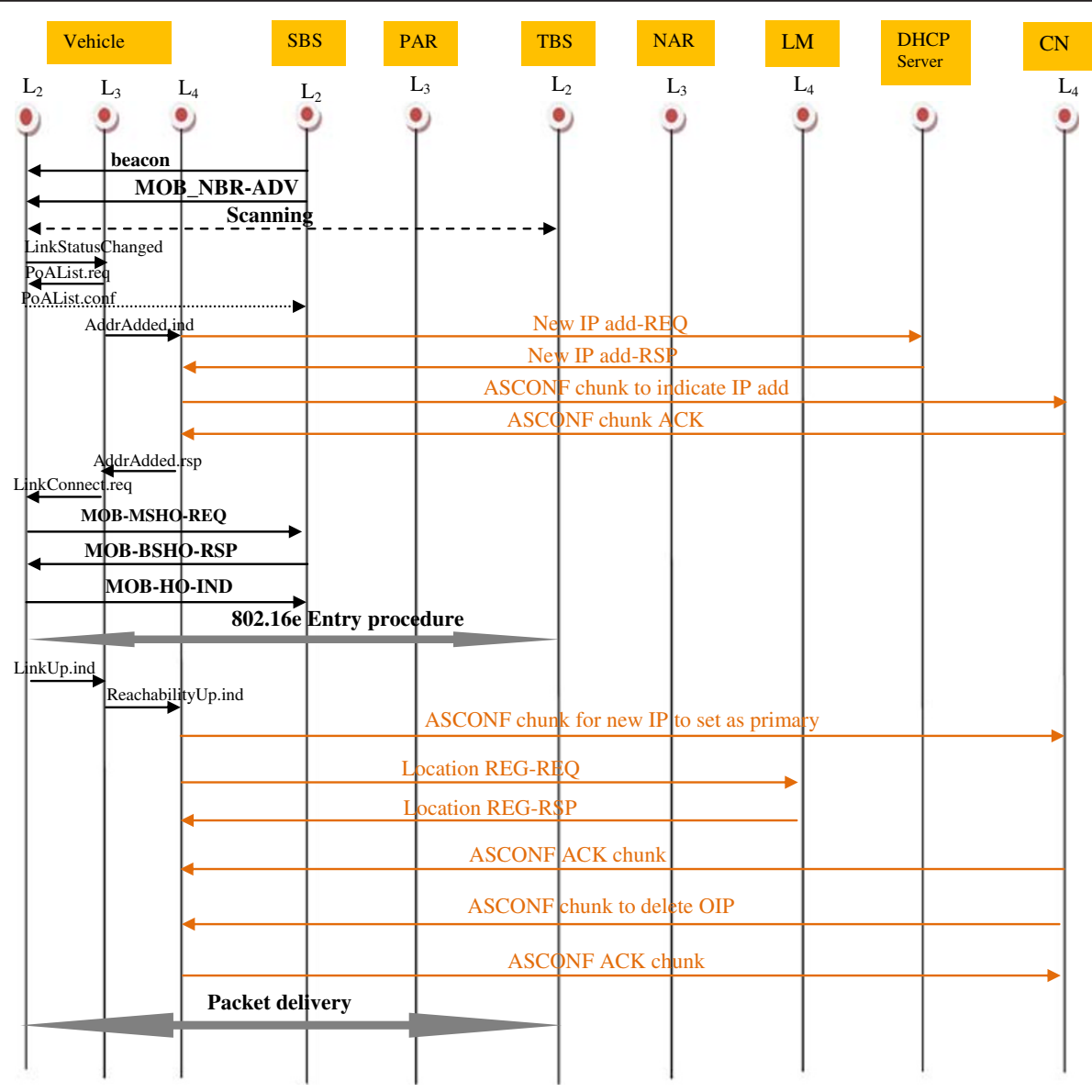

Figure 4 Timing diagram of the proposed cross-layer design. 


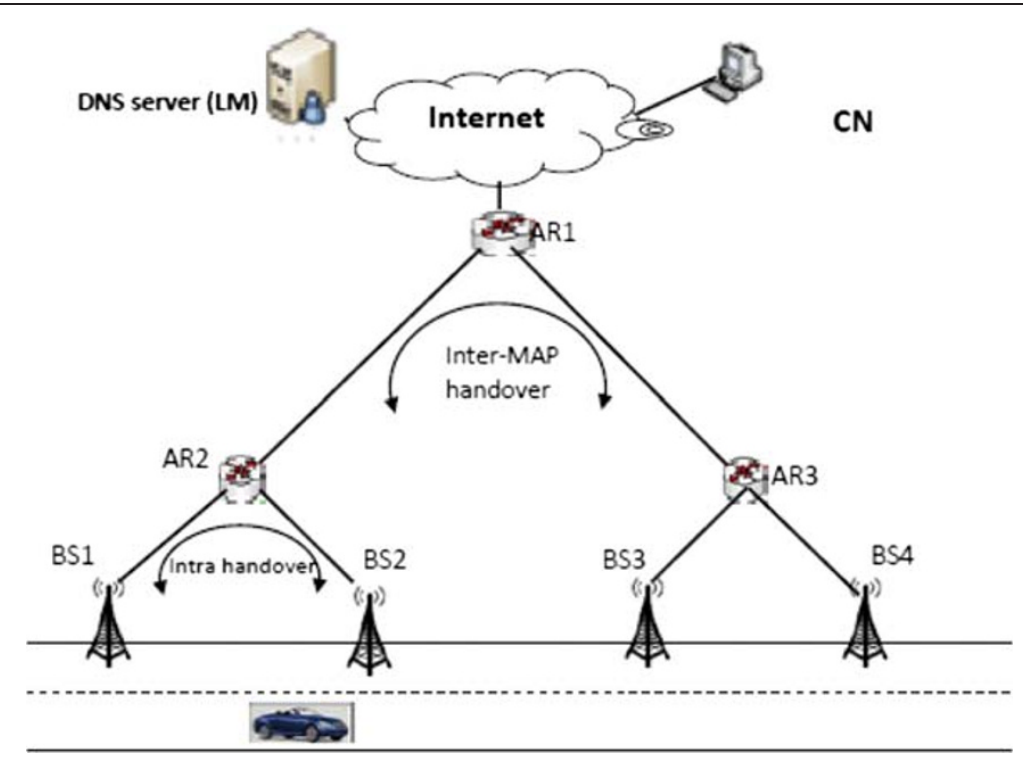

Figure 5 Network scenario.

a single-homed node sending traffic to the vehicle, which corresponds to the services like file downloading or web browsing by mobile users. However, LM uses by SIGMA as a network control entity.

\section{Results and discussion}

The simulation scenario taking accounts the MS speeds between 1 and $40 \mathrm{~m} / \mathrm{s} .40 \mathrm{~m} / \mathrm{s}$ (equals to $144 \mathrm{~km} / \mathrm{h}$ ), which is above the $100 \mathrm{~km} / \mathrm{h}$ limit described in IEEE 802.16 e for a seamless handover. When the vehicle is moving to the border of one BS in a certain speed, the signal quality of the SBS begins to degrade. Consequently, either the signal strength becomes low to initiate handover by sending (MOB-MSHO-REQ/RSP) messages. Alternatively, when the signal strength is below threshold (WiMAX standard $2 \mathrm{~dB}$ ) and the actual process of $\mathrm{HO}$ would be executed as (MOB-HO-IND) sends.

\section{Handover latency}

As mentioned earlier when applies SIGMA in a scenario appear in Figure 2, SIGMA's handover latency of is very nasty (15 ms of L2 delay) at a low speed of MN [15-17].

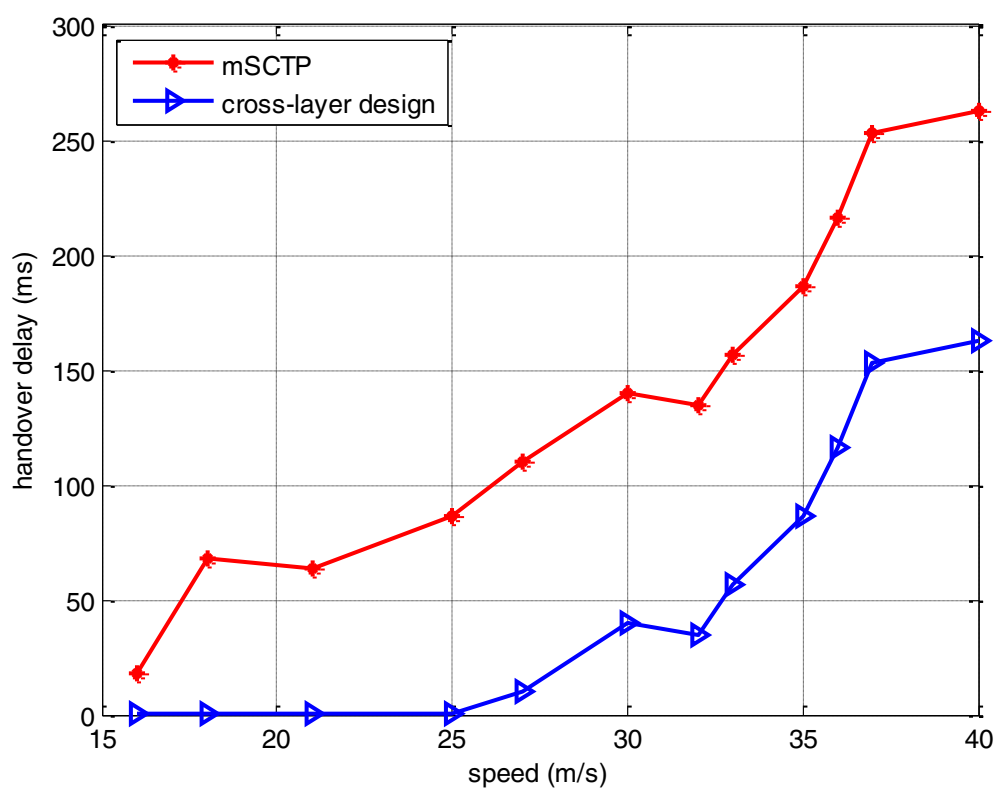

Figure 6 SIGMA \& cross-layer handover latency comparison. 
Table 2 Comparison of cross-layer and SIGMA throughputs for different speeds $(15-40 \mathrm{~m} / \mathrm{s})$

\begin{tabular}{lll}
\hline Protocols & Speeds & \\
\cline { 2 - 3 } & $\mathbf{1 5}$ & $\mathbf{4 0}$ \\
\hline SIGMA & Throughput (Mpbs) & \\
SCTPCd & 6 & 0.9 \\
\hline
\end{tabular}

On other hand, mSCTP experiences more handover delay in high-speed vehicle case. To eliminate these problems our proposed design uses SIGMA protocol cooperatively with mSCTP. However, using SIGMA in this design can be useful to drop duplication address detection delay using SIGMA's LM without more delay when updating vehicle location. In addition, using SIGMA's LM remains with no triangle routing problem of the packets' route between $\mathrm{CN}$ and vehicle in case of the high-speed vehicle [13]. That's because the $\mathrm{CN}$ always sends the packets directly to the vehicle's current IP address through LM. The handover delay for this cross-layer design calculated from vehicle to $\mathrm{CN}$. The disruption time due to $\mathrm{L} 2$ is about 10 $\mathrm{ms}$ and it is negligible for L3. For L4, it takes about 0.045 $\mathrm{ms}$ for ASCONF to SET-PRIMARY/DEL-IP, then from Equation (1) the total disruption time:

$$
\begin{aligned}
T_{\mathrm{HO}} & =\mathrm{L} 2+\mathrm{L} 4=10 \mathrm{~ms}+0.045 \mathrm{~ms}+\mathrm{RTT} \\
& =10.045+10=20 \mathrm{~ms}
\end{aligned}
$$

The handover delay between vehicle and $\mathrm{CN}$ depend on RTT between both is about $20 \mathrm{~ms}$. A comparison of

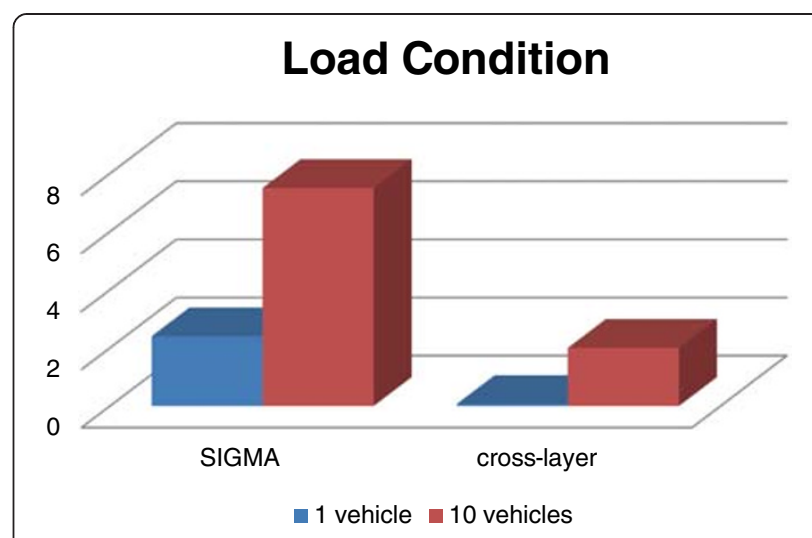

Figure 8 Network load of the cross-layer design and SIGMA.

these protocols and proposed design handover delays are shown in Figure 6.

\section{Throughput}

In this scenario, the throughput is considering the vehicle communicating to IEEE802.16e. When the vehicle speed increases to the higher value $(140 \mathrm{~km} / \mathrm{h}$ for WiMAX BS), the communication time in one coverage area of BS about $67 \mathrm{~s}$ for SCTPcd and handover latency is about $25 \mathrm{~ms}$. Thus for high-speed vehicle with a consecutive handover the vehicle cannot receive packets for $0.2 \mathrm{~s}$ due to handover, and then receives packets for $66.8 \mathrm{~s}$. As a result, the throughput of SCTPcd is much better than other SCTP in the environment of highly dynamic handover. Table 2 lists the throughput of SIGMA versus cross-layer design in speed of $15-40 \mathrm{~m} / \mathrm{s}$.

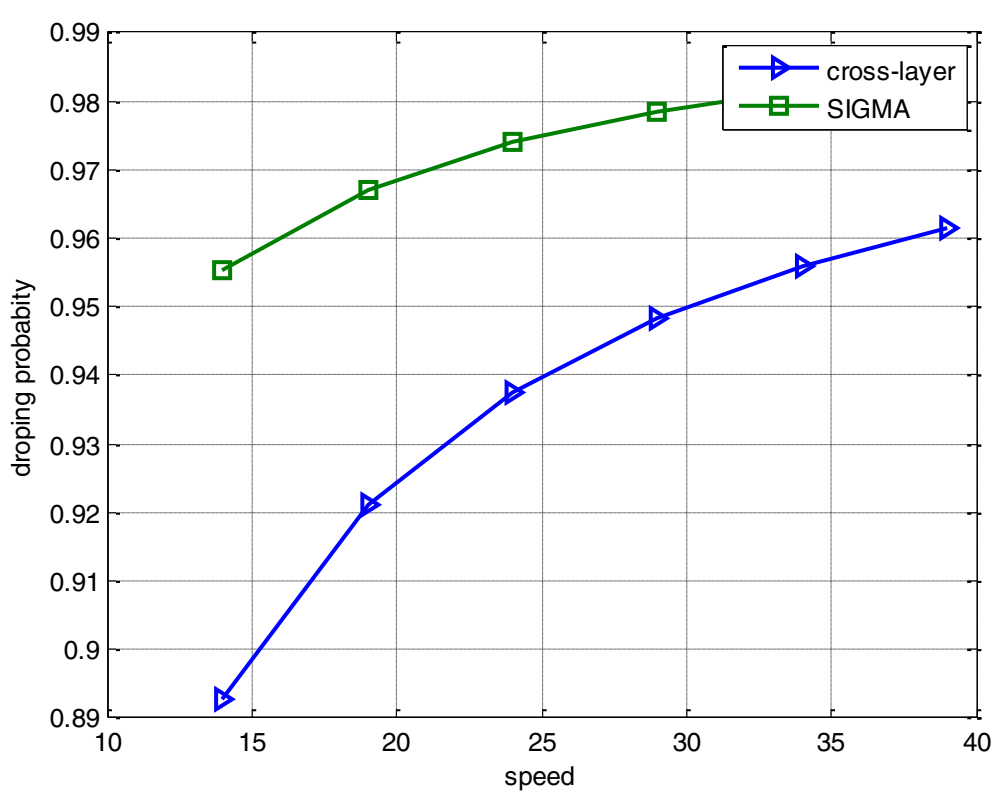

Figure 7 Dropping probability of the cross-layer design and SIGMA. 
From Figure 7, the dropping probability is very high in SIGMA design compare with our cross-layer design that is because of the consecutive handover in a short period. Also, Figure 8 depicted the handover delay time when the network load is high. To simplify the comparison, we test the simulation under network load of ten vehicles.

\section{Conclusion}

Internet accessibility in high-speed vehicles as V2I is more challenging and raise the need of least delay. In this article, an adaptive algorithm was proposed on L2 to support seamless handover in high-speed vehicles that connecting to a $\mathrm{CN}$ through the Internet. Moreover, a proposed cross-layer design at L2 has adapted L4 of SIGMA protocol design for global reachability to network. The crosslayer design dynamically updates L4 of handover at the time when network parameters (RSSI, SNR) degrade to unacceptable level. The results show that our design achieves better performance about $90 \%$ when speed is higher than SIGMA protocol design.

\section{Competing interests}

The authors declare that they have no competing interests.

\begin{abstract}
Acknowledgments
The authors would like to thank all those who contributed toward making this research successful. Also, we would like to thank all the reviewers for their insightful comments. The authors wish to express their gratitude to Ministry of Higher Education (MOHE), Malaysia and Research Management Center (RMC), Universiti. Teknologi Malaysia for the financial support of this project under GUP research grant no: Q-J I 30000.71 23-02 J93.
\end{abstract}

Received: 30 March 2012 Accepted: 21 June 2012

Published: 23 July 2012

\section{References}

1. Y Han, F Teraoka, An SCTP fast handover mechanism using a single interface based on cross-layer architecture. IEICE Trans 92-B(9), 2864-2873 (2009)

2. K Zhu, D Niyato, P Wang, E Hossain, D Kim, Mobility and handoff management in vehicular networks: a survey. Commun. Mob. Comput 00, $1-20(2009)$

3. YS Chen, $\mathrm{CH}$ Cheng, Network mobility protocol for vehicular ad hoc networks. IEEE in Wireless Communications and Networking Conference (WCNC), 1-6 (2009)

4. K Chiu, R Hwangy, Y Chen, Cross-layer design vehicle-aided handover scheme in VANETs. Wirel. Commun. Mob. Comput. 11(7), 916-928 (2011)

5. SK Sivagurunathan, J Jones, M Atiquzzaman, S Fu, Y Lee, Experimental comparison of handoff performance of SIGMA and mobile IP. Workshop on High Performance Switching and Routing (HPSR), 366-370 (2005). Hong Kong

6. DP Kim, S Koh, Analysis of handover latency for mobile IPv6 and mSCTP. J Inf. Process. Syst 4(3), 87-96 (2008)

7. DP Kim, SJ Koh, SW Kim, Analysis of SCTP Handover by Movement Patterns (Springer, Berlin, 2005), pp. 521-529

8. M Chang, M Lee, H Lee, Y Hong, J Park, An Enhancement of Transport Layer Approach to Mobility Support (Springer, Berlin, 2005), pp. 864-873

9. A Ezzouhairi, A Quintero, S Pierre, Towards cross layer mobility support in metropolitan networks. Elsevier Computer Communications 33, 202-221 (2010)

10. M Ratola, Which layer for mobility? in Comparing Mobile IPV6, HIP and SCTP, ed. by (Seminar on Internetworking, 2004), pp. 1-9

11. N Yaakob, F Anwar, Seamless handover mobility schemes over high speed wireless environment (International Conference on Electrical Engineering and Informatics, Indonesia, 2007). Ref No.2

12. C Ming, M Shu, TZ Heng, PFC: a packet forwarding control scheme for vehicle handover over the ITS networks. Comput. Commun, 2815-2826 (2007)
13. QB Mussabbir, W Yao, Z Niu, X. Fu, Optimized FMIPv6 using IEEE $802.21 \mathrm{MIH}$ services in vehicular networks. IEEE Trans. Veh. Technol. VOL. 56(6), 33973407 (2007)

14. S Fu, M Atiquzzaman, Survivability evaluation of SIGMA and mobile IP. Wirel. Commun, 524-528 (2007)

15. S Fu, M Atiquzzaman, Architecture and performance of SIGMA: a seamless mobility architecture for data networks. IEEE International Conference on Communications 5, 3249-3253 (2005)

16. S Fu, M Atiquzzaman, Handover latency comparison of SIGMA, FMIPv6, HMIPv6, and FHMIPv6. IEEE Proceeding GLOBECOM, 3809-3813 (2006)

17. P Chowdhury, S Reaz, T Chun Lin, M Atiquzzaman, Design issues for SIGMA: seamless IP diversity based generalized mobility architecture (Technical Report, 2006)

18. I. Aydin, CC Shen, Evaluating cellular SCTP over one-hop wireless networks. 2, 826-830 (2007)

19. Y Han, F Teraoka, SCTPfx: a fast failover mechanism based on cross-layer architecture in SCTP multihoming (AINTEC'08, Bangkok, Thailand, 2008), pp. 113-122

20. H Jubara, S Ariffin, Evaluation of SIGMA and SCTPmx for high handover rate vehicle. Int. J. Adv. Comput. Sci. Appl 2(7), 169-173 (2011)

doi:10.1186/1687-1499-2012-229

Cite this article as: Jubara et al:: Adaptive transport layer protocol for highly dynamic environment. EURASIP Journal on Wireless Communications and Networking 2012 2012:229.

\section{Submit your manuscript to a SpringerOpen ${ }^{\circ}$ journal and benefit from:}

- Convenient online submission

- Rigorous peer review

- Immediate publication on acceptance

- Open access: articles freely available online

- High visibility within the field

- Retaining the copyright to your article

Submit your next manuscript at $>$ springeropen.com 